\title{
O giro decolonial e suas contribuições para a análise da proteção social na América Latina
}

The decolonial twist and its contributions to the analysis of the social protection in Latin America

\author{
Nayara Cristina Bueno* \\ Lislei Teresinha Preuss**
}

\begin{abstract}
Resumo
Na América Latina, especialmente no Brasil, o tema da proteção social, seu processo de institucionalização e sua configuração, tem sido abordado, historicamente, a partir de perspectiva teórica e prática europeia; por isso, este estudo busca contribuir com uma abordagem do ponto de vista do lado subalterno das relações de poder. Diante disso, o objetivo é refletir sobre a proteção social na América Latina a partir da perspectiva decolonial. A pesquisa é de natureza qualitativa e contou com revisão bibliográfica. São apresentadas as perspectivas de análises da proteção social construídas historicamente, em especial as classificações de regimes de bem-estar e as teorias explicativas. O trabalho demonstra que a análise, na perspectiva decolonial, permite identificar elementos (in) visíveis na literatura sobre os sistemas de proteção social. As contribuições partem da indivisibilidade entre economia e cultura; considera a perspectiva da interseccionalidade raça, classe, gênero como estruturante do capitalismo periférico; e demonstra que o sistema de proteção social europeu, transportado para América, reforça hierarquias e papéis sociais de classe, raça, gênero, sendo esta, portanto, uma das faces da colonialidade do poder.
\end{abstract}

Palavras-chave: Proteção social. Regimes de bem-estar. Colonialidade global. Interseccionalidade raça, classe, gênero. América Latina.

\begin{abstract}
In Latin America, especially in Brazil, the topic of the social protection, its institutionalization process and its configuration, has been approached, historically, from an European theoretical and practical perspective, therefore, this study seeks to contribute with an approach from the point view of the subordinate side of the power relations. In light of this, the objective is to reflect on social protection in Latin America from a decolonial perspective. The research is from a qualitative nature and had a bibliographic review. Historically constructed perspectives for social protection analyzes are presented, in particular the classifications of welfare regimes and explanatory theories. The work demonstrates that the analysis, in the decolonial perspective, allows us to identify (in) visible elements in the literature about the social protection systems. The Contributions start from the indivisibility between the economy and the culture; it considers the perspective of race, class, gender intersectionality as structuring peripheral capitalism; and, it demonstrates that the European social protection system, transported to America, reinforces hierarchies and social roles of class, race, gender, which is, therefore, one of the faces of the coloniality of power.
\end{abstract}

Keywords: Social protection. Wellness regimes. Global. Coloniality. Intersectionality of Race, class, gender. Latin America.

\footnotetext{
* Mestre em Serviço Social e Política Social pela Universidade Estadual de Londria (UEL). Professora do Departamento de Serviço Social da Universidade Estadual do Centro-Oeste (UNICENTRO). Doutoranda em Ciências Sociais aplicadas pela Universidade Estadual de Ponta Grossa (UEPG).

** Doutora em Serviço Social pela Pontifícia Universidade Católica do Rio Grande do Sul. Professora adjunta da Universidade Estadual de Ponta Grossa e do Programa de Pós-Graduação Interdisciplinar em Ciências Sociais Aplicadas.
} 


\section{Introdução}

A proposta de construção de uma análise da proteção social na América Latina em uma perspectiva epistemológica, proveniente do lado subalterno da diferença colonial, surgiu na disciplina de Epistemologia e Método nas Ciências Sociais do Programa de PósGraduação em Ciências Sociais Aplicadas da Universidade Estadual de Ponta Grossa - UEPG no primeiro semestre de 2019.

Segundo Grosfoguel (2008), as perspectivas epistêmicas subalternas são uma forma de conhecimento que situa o sujeito de enunciação ao lado subalterno das relações de poder. $\mathrm{O}$ autor demonstra que se construiu uma hierarquia de conhecimento superior e inferior e, consequentemente, de povos superiores e inferiores, a partir da estratégia epistêmica de esconder o lugar do sujeito de enunciação, como se todo conhecimento produzido no processo de dominação e expansão colonial europeia/euro-americana fosse neutro, objetivo, verdadeiro e universal.

Diante disso, as leituras e discussões sobre as ciências sociais na perspectiva póscolonial despertaram reflexões sobre as pesquisas realizadas pela autora que reproduziam a visão eurocêntrica sobre a proteção social brasileira. Com exceções, os estudos sobre a proteção social na América Latina, especialmente no Brasil, partem das experiências europeias e norte-americana do período 1930-1945 como referência. A análise do processo histórico de desenvolvimento se volta ao que falta aos países para alcançar aquele padrão de proteção social.

Isso ocorre, em parte, porque a modernidade na perspectiva eurocêntrica está relacionada ao urbano e industrial, como se todas as sociedades tivessem que buscar esse padrão de desenvolvimento. Por outro lado, ao estudar sobre a perspectiva decolonial, identificamos que as sociedades latino-americanas, antes do processo de colonialismo, possuíam distintas formas civilizatórias, inclusive com sinais de modernidade, como o racional científico, a secularização do pensamento, a organização da vida social e reservas para momentos de dificuldades. (QUIJANO, 2005).

Os estudos sobre a proteção social na região apontam os limites do padrão europeu na região, mas poucos avançam na análise das especificidades históricas, sociais, 
econômicas e políticas que apresentam limites e possibilidades de desenvolvimento de políticas sociais voltadas a superar hierarquias impostas e estratificações construídas.

Diante disso, é necessário reconhecer as contribuições dos diferentes estudos, mas também questionar a proteção social em sua totalidade no sistema-mundo, ou seja, enquanto se constrói sistemas de proteção social de caráter "universal" nos países centrais, os (as) trabalhadores (as) dos países dependentes sobrevivem por meio da superexploração do trabalho, desprotegido, mal pago.

Ademais, o lugar subalterno no sistema-mundo construído historicamente para a América Latina dificulta as tentativas de se desenvolver sociedades comprometidas com a proteção social de seus membros, baseada em vínculos sociais que superem aqueles estabelecidos pelo modo capitalista de produção.

Assim, pergunta-se: é possível construir sistemas de proteção social a partir da realidade latino-americana, que considerem as estruturas hierárquicas de raça, classe, gênero, sexualidade que foram impostas a esses países no processo de colonização e ainda se mantêm? Este trabalho irá perseguir esse questionamento.

Diante disso, o objetivo é refletir sobre a proteção social a partir da perspectiva decolonial. Para isso, foi realizado um trabalho de natureza qualitativa, que contou com revisão bibliográfica. $\mathrm{O}$ texto está organizado em duas partes. A primeira discute as classificações de regimes de bem-estar na região e as teorias explicativas da proteção social. A segunda parte procura identificar as possibilidades de análise decolonial da proteção social, destacando a necessidade de melhor compreender as especificidades históricas da região e, a partir disso, (re)pensar possibilidades de proteção social.

\section{As Análises da Proteção Social na América Latina}

Discutir sobre proteção social na sociedade capitalista pressupõe demarcar a perspectiva teórica que se adota e esclarecer quais práticas se defende ou propõe. Segundo Pereira (2013), foram construídas, historicamente, teorias e ideologias conflitantes que orientam as ações desenvolvidas pelos Estados na área. Há, portanto, tipologias relacionadas às escolas teóricas que se dedicam ao estudo e, também, aos modelos implementados ao redor do mundo. 
A proteção social visa atender às necessidades humanas de reprodução social e autonomia, ou seja, aquilo que é indispensável para o padrão estabelecido por uma sociedade. Essas necessidades são históricas, mas também objetivas e universais e referem-se a "precondições universais que, uma vez atendidas, possibilitam a participação social no sentido democrático". (PEREIRA, 2013, p. 55).

Segundo Pereira (2013), as necessidades humanas básicas estão associadas a direitos morais e, posteriormente, sociais, os quais são atendidos por meio das políticas sociais, por isso o Estado tem papel central nesta discussão, é ele quem garante a vinculação das necessidades humanas à noção de direito.

A política social, por sua vez, possui caráter contraditório, uma vez que atende uma necessidade humana de proteção e cuidado, contudo, é expressão do Estado capitalista na manutenção e reprodução da sociedade de classes. Diante disso, a análise da proteção social pública não pode se dar deslocada do movimento da sociedade capitalista e das relações sociais de trabalho.

Portanto, as mudanças na proteção social são geradas tanto pelas capacidades desenvolvidas pelos países nos períodos anteriores quanto pelas escolhas políticas fundadas nas dimensões objetivas (econômicas) e subjetivas (qual sociedade queremos construir?). Assim, família, Estado, mercado e comunidade têm desenvolvido diferentes papéis nesse processo, variando de país para país.

Em relação aos estudos sobre a proteção social, Pereira (2013) afirma que são poucos os que se voltam para o seu prisma processual, contraditório e dialético. Inclusive, segundo Andrade (2012), na América Latina os estudos que comparam as práticas desenvolvidas nos países privilegiam os gastos sociais, as diversas formas de distribuição dos serviços e seus efeitos do ponto de vista da desfamiliarização e da desmercadorização.

Dessa forma, a tendência nos estudos comparados são as pesquisas desenvolvidas com base em indicadores quantitativos, usados de forma homogênea para medir as diferentes realidades da região e, ainda, após os estudos de Esping-Andersen (1991) em 18 países europeus na década de 1990, foram incorporados nas pesquisas na região indicadores que medem o grau de participação da família e do mercado na proteção social, por isso as expressões desfamilismo e desmercadorização. 
Contudo, há vários problemas em se buscar uma aplicação mecânica da tipologia de Esping-Andersen (1991) na América Latina devido às suas especificidades, entre elas: a informalidade e precarização do trabalho; o baixo investimento estatal em políticas sociais; a heterogeneidade da região; e, também, a forte presença da família e da comunidade na provisão de bem-estar (KERSTENETZKY, 2012). Características essas que se diferem das sociedades analisadas pelo autor, uma vez que a construção de seus estudos parte da realidade europeia em específico.

Alencar (2019) afirma que os estudos de Esping-Andersen (1991) inviabilizam o trabalho doméstico feminino, realizado na esfera doméstica e dos cuidados, uma vez que os estudos do autor privilegiaram o homem branco europeu que possui relação com o mercado de trabalho formal e as mulheres não se relacionam com o mercado da mesma forma que os homens devido à realização do trabalho na esfera da "reprodução".

Além disso, a entrada da mulher no mercado do trabalho não interferiu nas "obrigações domésticas", por isso, as políticas sociais europeias "hierarquizaram e solidificaram os papéis sociais de gênero", enquanto os homens possuíam status de trabalhador, as mulheres acessam os benefícios sociais enquanto mães e/ou esposas, ou seja, como trabalhadoras não pagas (ALENCAR, 2019, p. 50, grifo do autor). Esse trabalho realizado pelas mulheres, além de inviabilizado, também não é valorizado, mesmo sendo indispensável para o processo de reprodução social do trabalhador.

Portanto, identificam-se limites nos estudos comparados europeus e, mesmo assim, eles são transportados para América Latina. Andrade (2012) demonstrou que as dificuldades nas análises sobre os sistemas de bem-estar na região, em especial os estudos de forma comparada, ocorrem devido às definições enraizadas no Estado de Bem-estarsocial europeu, à vinculação com a social democracia e ao enfoque quantitativo (tempo e recurso). Contudo, sabe-se que um governo social democrata na Europa, assim como um trabalhador europeu, difere muito das experiências da América Latina.

Cada país possui uma formação da sociedade capitalista específica e, consequentemente, a formação estatal irá corresponder ao produto da contradição dessa sociedade, por isso Cunha (2017) afirma que é pela análise da sociedade que se compreende a atuação e a função desempenhada pelo Estado em determinadas condições históricas concretas. 
Nesse aspecto reside a complexidade dos estudos de proteção social porque é necessário compreender o processo histórico de desenvolvimento das sociedades e como as instituições: Estado, mercado, família e comunidade se inter-relacionam para o atendimento das necessidades básicas dos indivíduos, tendo ainda a centralidade no Estado por meio das políticas sociais públicas. Além disso, é preciso considerar como se dá a inserção do país no sistema capitalista mundial e como isso influencia na destinação do fundo público (redistribuição).

O Estado não pode ser analisado como neutro ou como possuidor de uma universalidade perante a sociedade e os interesses conflitantes existentes, porque o Estado é resultado e, ao mesmo tempo, constituinte da sociedade capitalista, portanto, representa contraditoriamente interesses de classes. (CUNHA, 2017).

Marx (2013) demonstrou na discussão sobre a lei geral da acumulação capitalista que a produção da riqueza baseada na exploração da força de trabalho, ao mesmo tempo que possibilita ao capitalista acumular riqueza, gera o pauperismo da classe trabalhadora. Nesse sentido, a única forma de colocar limites ao capital é o processo de organização da classe trabalhadora. A luta social e a luta de classes são instrumentos utilizados pela classe trabalhadora para pressionar o Estado a impor limites à sua exploração.

É por isso que a proteção social estatal atende interesses tanto do capital (controla tensões e age na manutenção da propriedade privada e das relações capitalistas) quanto do trabalho (garante $o$ acesso a determinados direitos sociais conquistados historicamente). E de seu formato depende a correlação de forças em determinada sociedade. Com isso, percebe-se que não se trata de algo linear, em que uma vez reconhecido determinado direito ele irá sempre existir ou, ainda, de um processo progressivo de alcance civilizatório dos países; pelo contrário, é um processo de constante disputa, em que avanços e retrocessos estão presentes.

Diante disso e a partir da luta de classes, o Estado irá desenvolver sistemas de proteção social que, conforme Giovanni (1998, p. 10), referem-se "as formas - às vezes mais, às vezes menos institucionalizadas - que as sociedades constituem para proteger parte ou o conjunto de seus membros." O autor afirma ainda que "Tais sistemas decorrem 
de certas vicissitudes da vida natural ou social, tais como a velhice, a doença, o infortúnio e as privações". Portanto, estão vinculadas aos sistemas de seguridade social.

A seguridade social tem sido o núcleo central da proteção social. Vianna (2011) afirma que há duas vias de explicação sobre a seguridade social, uma baseada na ideia de seguro (contributiva) e outra vinculada aos direitos sociais de cidadania (não contributiva). A primeira via, vinculada ao trabalho formal e urbano, foi a que mais se desenvolveu historicamente. Essa configuração da seguridade social europeia, exportada para os países da América Latina, tem sido obstáculo para a garantia da proteção social, devido às especificidades já citadas anteriormente, mas, principalmente, devido ao formato do mercado de trabalho.

Mesmo os países da região que avançaram na definição de políticas não contributivas, vinculadas a ideia de seguridade social, como é o caso do Brasil, ainda mantém a centralidade no sistema contributivo. $\mathrm{O}$ acesso a políticas não contributivas é seletivo e/ou focalizado em grupos específicos, o que demonstra a característica subsidiária, ou seja, o Estado apenas age quando a família e o mercado não atendem às necessidades dos indivíduos.

Destaca-se, ainda, que, conforme afirma Vianna (2011), há uma imprecisão conceitual em relação à seguridade social, uma vez que sua definição enfrenta dificuldades de torná-la uma categoria universal. Dificuldades, estas, vernaculares (línguas e simbolismo), históricas (trajetórias e especificidades econômicas, sociais e políticas) e da variedade de estruturas de governos que caracterizam os Estados nacionais.

Essa imprecisão conceitual da seguridade social dificulta a realização de estudos comparados, uma vez que os países organizam de diferentes formas os sistemas de seguridade social, por isso a necessidade de estudos que privilegiam as particularidades de cada país, mais do que comparar variáveis quantitativas. De modo geral, na América Latina, os países têm integrado nesses sistemas as políticas previdenciárias e de saúde, com parcerias público-privadas.

Em relação às classificações dos sistemas de proteção social da América Latina, há uma diversidade de análises disponíveis na literatura, as quais privilegiam: o caráter histórico-temporal dos sistemas de seguridade social (Mesa-Lago), o gasto social (CEPAL), 
índices compostos (Filgueira), análises estatísticas (Franzoni), análises de capacidades

(Cecchini) e grau de proteção via Estado (Cantu), conforme descrito no quadro 01 :

Quadro 1 - Fundamentos e classificações dos regimes de bem-estar da América Latina

\begin{tabular}{|c|c|c|c|c|}
\hline Autor/a & Fundamento & \multicolumn{3}{|c|}{ Classificação } \\
\hline $\begin{array}{l}\text { Mesa- } \\
\text { Lago } \\
(1978)\end{array}$ & $\begin{array}{l}\text { Análise do caráter } \\
\text { histórico-temporal } \\
\text { da estruturação dos } \\
\text { sistemas de } \\
\text { seguridade social. }\end{array}$ & $\begin{array}{l}\text { Pioneiros } \\
\text { Iniciaram nos } \\
\text { anos 1920: } \\
\text { Brasil, Chile, } \\
\text { Argentina, } \\
\text { Uruguai } \\
\text { Cuba. }\end{array}$ & $\begin{array}{l}\text { Intermediários } \\
\text { Estruturaram } \\
\text { nos anos 1940: } \\
\text { Costa Rica, } \\
\text { Panamá, } \\
\text { México, Peru, } \\
\text { Colômbia, } \\
\text { Bolívia, Equador, } \\
\text { Paraguai e } \\
\text { Venezuela. }\end{array}$ & $\begin{array}{l}\text { Tardios } \\
\text { Implementaram } \\
\text { nos anos de } 1950 \\
\text { e 1960: República } \\
\text { Dominicana, } \\
\text { Guatemala, El } \\
\text { Salvador, } \\
\text { Nicarágua, } \\
\text { Honduras e Haiti. }\end{array}$ \\
\hline $\begin{array}{l}\text { Cepal } \\
(1998)\end{array}$ & $\begin{array}{l}\text { Análise do } \\
\text { percentual do PIB } \\
\text { empregado em } \\
\text { gastos sociais, bem } \\
\text { como o gasto per } \\
\text { capita com medidas } \\
\text { de proteção social, } \\
\text { entre elas, saúde e } \\
\text { educação, no ano de } \\
\text { 1998. }\end{array}$ & $\begin{array}{l}\text { Gasto social } \\
\text { superiores } \\
\text { a } 400 \text { dólares } \\
\text { per capita: } \\
\text { Argentina, } \\
\text { Uruguai, Brasil, } \\
\text { Chile, Panamá } \\
\text { e Costa Rica. }\end{array}$ & $\begin{array}{l}\text { Gastos } \\
\text { intermediários } \\
\text { que oscilavam } \\
\text { entre } 200 \text { e } 400 \\
\text { dólares per } \\
\text { capita: } \\
\text { Colômbia, } \\
\text { México } \\
\text { Venezuela. }\end{array}$ & 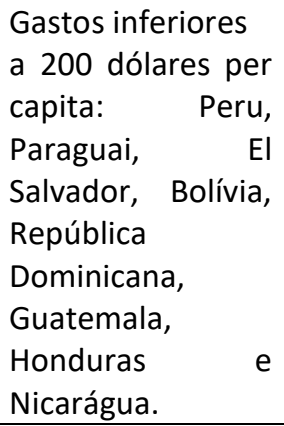 \\
\hline $\begin{array}{l}\text { Filgueira } \\
\text { (1997) }\end{array}$ & $\begin{array}{l}\text { Análise de índices } \\
\text { compostos: } \\
\text { população coberta, } \\
\text { pobreza e } \\
\text { desigualdade. E de } \\
\text { características } \\
\text { demográficas: } \\
\text { esperança de vida, } \\
\text { analfabetismo e } \\
\text { taxa de mortalidade. }\end{array}$ & $\begin{array}{l}\text { Universalismo } \\
\text { Estratificado: } \\
\text { Argentina, } \\
\text { Uruguai e Chile. }\end{array}$ & $\begin{array}{l}\text { Regimes Duais: } \\
\text { Brasil e México. }\end{array}$ & $\begin{array}{l}\text { Regimes } \\
\text { Excludentes: } \\
\text { República } \\
\text { Dominicana, } \\
\text { Guatemala, } \\
\text { Honduras, El } \\
\text { Salvador, } \\
\text { Nicarágua, Bolívia } \\
\text { e Equador. }\end{array}$ \\
\hline $\begin{array}{l}\text { Franzoni } \\
(2007)\end{array}$ & $\begin{array}{l}\text { Análise estatística, } \\
\text { contemplando } \\
\text { informações sobre a } \\
\text { estrutura social, } \\
\text { econômica e das } \\
\text { políticas públicas } \\
\text { em } 18 \text { países. } \\
\text { Incorpora categorias } \\
\text { como (des) } \\
\text { familiarização e } \\
\text { (des) } \\
\text { mercadorização. }\end{array}$ & $\begin{array}{l}\text { Estatal } \\
\text { Produtivista: } \\
\text { Chile } \\
\text { Argentina. }\end{array}$ & $\begin{array}{l}\text { Estatal } \\
\text { Protecionista: } \\
\text { Brasil, Uruguai, } \\
\text { Costa Rica e } \\
\text { México. }\end{array}$ & $\begin{array}{l}\text { Familiarista: } \\
\text { Colômbia, } \\
\text { Equador, } \\
\text { Salvador, } \\
\text { Guatemala, Peru, } \\
\text { República } \\
\text { Dominicana e } \\
\text { Venezuela, Bolívia, } \\
\text { Honduras, } \\
\text { Nicarágua } \\
\text { Paraguai. }\end{array}$ \\
\hline $\begin{array}{l}\text { Cecchini } \\
(2014)\end{array}$ & $\begin{array}{l}\text { Análise de } \\
\text { capacidades: } \\
\text { gerar renda via } \\
\text { mercado; Estado } \\
\text { prover de sustento; }\end{array}$ & $\begin{array}{l}\text { Lacunas } \\
\text { pequenas na } \\
\text { Proteção } \\
\text { Social: }\end{array}$ & $\begin{array}{l}\text { Lacunas } \\
\text { intermediárias } \\
\text { na Proteção } \\
\text { Social: }\end{array}$ & $\begin{array}{lr}\text { Lacunas } & \text { grandes } \\
\text { na } & \text { Proteção } \\
\text { Social: } & \\
\text { Bolívia, } & \text { El } \\
\text { Salvador, } & \\
\end{array}$ \\
\hline
\end{tabular}




\begin{tabular}{|l|l|l|l|l|l|}
\hline & $\begin{array}{l}\text { proteção a grupos } \\
\text { vulneráveis. }\end{array}$ & $\begin{array}{l}\text { Argentina, } \\
\text { Brasil, Costa } \\
\text { Rica, Chile, } \\
\text { Panamá, } \\
\text { Uruguai, } \\
\text { Venezuela. }\end{array}$ & $\begin{array}{l}\text { Colômbia, } \\
\text { Equador, } \\
\text { México, Peru e } \\
\text { República } \\
\text { Dominicana. }\end{array}$ & $\begin{array}{l}\text { Honduras, } \\
\text { Guatemala, } \\
\text { Nicarágua. }\end{array}$ \\
\hline $\begin{array}{l}\text { Cantu } \\
(2015)\end{array}$ & $\begin{array}{l}\text { Análise do grau de } \\
\text { proteção via Estado, } \\
\text { grau de } \\
\text { mercantilização, de de } \\
\text { estratégias } \\
\text { subsistência das } \\
\text { famílias. }\end{array}$ & $\begin{array}{l}\text { Liberal radical: } \\
\text { Argentina, } \\
\text { Brasil, Costa } \\
\text { Rica e Uruguai }\end{array}$ & Chile, México & $\begin{array}{l}\text { Excludente } \\
\text { familista: } \\
\text { Bolívia, Colômbia, } \\
\text { Equador, } \\
\text { Guatemala, } \\
\text { Panamá, Paraguai, } \\
\text { Peru, Venezuela. }\end{array}$ & $\begin{array}{l}\text { Excludente } \\
\text { migratório } \\
\text { Honduador, } \\
\text { Nicarágua. }\end{array}$ \\
\hline
\end{tabular}

Fonte: Adaptado de Andrade (2012) e Viana, Fonseca e Silva (2017).

Conforme o quadro 1 , os sistemas de proteção social estatais começaram a ser implementados na América Latina na década de 1920, contudo, observa-se que alguns países somente implementaram em décadas recentes (1950/1960). Os países tardios, na classificação de Mesa-Lago (1978), tiveram dificuldades em ampliar a proteção social nos anos seguintes, como se pode perceber no quadro 1 , pois permaneceram nas demais classificações como os mais excludentes.

Por outro lado, ser um país pioneiro na implementação da proteção social não significa ser, necessariamente, aquele que irá ampliar a proteção social pública em um processo sempre de avanço. O quadro 1 demonstra que os países, nos diferentes momentos históricos de elaboração dos estudos e, ainda, conforme os indicadores utilizados, variam em maior ou menor grau de proteção social.

Antía (2018) demonstra ainda que, além das tipologias, encontra-se na literatura classificações relacionadas a três grandes períodos de evolução das políticas sociais: 1 ) surgimento e consolidação (1920 a 1980); 2) etapa da reforma neoliberal das políticas sociais (1980-1990); e 3) fase de expansão segmentada (2000 a atualidade) ${ }^{1}$. Esses estudos apontam as tendências em cada período histórico. A mesma autora afirma que a maior parte da bibliografia sobre o tema na América Latina se concentra na caracterização dos regimes de políticas sociais, em detrimento de suas causas.

Há muitos estudos sobre as teorias explicativas quando se trata dos Estados de Bem-Estar europeus que se vinculam às diferentes formas de compreender a realidade

\footnotetext{
${ }^{1}$ Poderíamos incluir uma 4ạ fase na classificação de Antía (2018), após a segunda década do século XXI, com o avanço da direita e extrema direita na região.
} 
social e as categorias que são privilegiadas nesses estudos. Arretche (1995) demonstra que algumas privilegiam a ordem econômica, partindo da vinculação entre o desenvolvimento da industrialização, acumulação e a necessidade de legitimação da ordem capitalista e a proteção social pública enquanto constitutiva e constituinte desse processo.

Há também as explicações de ordem política, quais sejam: ampliação progressiva de direitos; resultado de acordos entre capital e trabalho; capacidade de mobilização da classe trabalhadora; e configuração histórica das estruturas estatais e instituições. (ARRETCHE, 1995).

Especificamente sobre a América Latina, Antía (2018) demonstra que, ainda que com diferentes perspectivas teóricas e metodológicas, os estudos sobre a emergência e desenvolvimento da proteção social destacam os níveis de industrialização, a presença de instituições democráticas e as diferentes formas de integração dos trabalhadores na esfera política. Pode-se observar os principais estudos elencados pela autora no quadro 2 :

Quadro 2 - Fatores de relevância presentes nos estudos explicativos de emergência e desenvolvimento dos regimes de bem-estar na América Latina

\begin{tabular}{|c|c|c|c|}
\hline Autor & \multicolumn{3}{|c|}{ Fatores } \\
\hline $\begin{array}{l}\text { Filgueira } \\
(2005, \\
2007)\end{array}$ & $\begin{array}{l}\text { Papel da elite na busca de } \\
\text { apoio popular. }\end{array}$ & $\begin{array}{l}\text { Papel da elite na cooptação do } \\
\text { setor popular. }\end{array}$ & $\begin{array}{l}\text { Países com elites } \\
\text { depredadoras. }\end{array}$ \\
\hline $\begin{array}{l}\text { Segura- } \\
\text { Ubiergo } \\
(2007)\end{array}$ & $\begin{array}{l}\text { Nível de } \\
\text { econômico desenvolvimento } \\
\text { industrialização e aumento da } \\
\text { capacidade fiscal dos Estados. }\end{array}$ & $\begin{array}{l}\text { Expansão de } \text { massa dos } \\
\text { trabalhadores capazes de } \\
\text { pressionar o Estado para } \\
\text { criação de programas sociais. }\end{array}$ & $\begin{array}{l}\text { Tradição democrática e } \\
\text { poder da esquerda } \\
\text { política e dos } \\
\text { movimentos sindicais. }\end{array}$ \\
\hline $\begin{array}{l}\text { Haggard y } \\
\text { Kaufman } \\
(2008)\end{array}$ & Realinhamento crítico. & $\begin{array}{l}\text { Modelo de desenvolvimento } \\
\text { econômico. }\end{array}$ & Regime político. \\
\hline
\end{tabular}

Fonte: Adaptado de Antía (2018).

Tanto fatores políticos (papel da elite na busca de apoio popular; expansão das massas de trabalhadores capazes de pressionar o Estado; democracia; movimentos de esquerda e movimentos sindicais) quanto fatores econômicos (desenvolvimento; industrialização) são apontados pelos autores. Mas carecem estudos sobre a relação entre regimes ditatoriais e políticas sociais (ANTÍA, 2018). O Brasil é um exemplo, pois ocorreram ampliações de políticas sociais em períodos ditatoriais, podemos citar: direitos trabalhistas na década de 1930/40 e ampliação dos direitos previdenciários na década de 1970 . 
Por fim, destaca-se que há limitadores nas pesquisas comparativas que procuram universalizar a coleta de dados e utilizar as mesmas variáveis, maior parte quantitativa, para conhecer sistemas de proteção social com diferentes formações históricas, sociais e políticas.

Kerstenetzky (2012, p. 164) demonstra que a heterogeneidade interna da América Latina abriga "profundas dessemelhanças entre as poucas afinidades". Entre as semelhanças a autora cita "os elevados níveis de desigualdade, os baixos patamares proporcionais ao gasto social e carga tributária e o passado (quase) comum de colonização ibérica." Entre as dessemelhanças a autora apresenta indicadores de recursos e desempenho da região e destaca aspectos como recursos, prioridades políticas e bemestar.

Zemelman (apud KRAWCZYK; MORAES, 2003) afirma que o desafio dos estudos comparados está na capacidade de comparar as articulações que faz um fenômeno, assim como se configura sua especificidade. O autor propõe que se compare a situação de historicidade, ou seja, os produtos dos processos que convergiram nele e suas possibilidades. Analisar a realidade social enquanto um processo dinâmico que transcende o que é mensurável, Zemelman (apud KRAWCZYK; MORAES, 2003) propõe que todo "produto" ou "problema social" seja lido por suas dinâmicas constitutivas ou processo que possui diferentes níveis de realidade articulados. As relações entre esses níveis e seus efeitos determinam sua especificidade e, ainda, essas relações são como nós articulares, cuja importância é que constituem espaços onde os processos podem ser aprimorados em uma direção ou outra.

Contudo, como já assinalado neste trabalho, são poucos estudos de proteção social que partem de uma análise processual, histórica, dialética e a partir da totalidade. Quando se pensa na totalidade da proteção social, a discussão, além da análise da relação do Estado, mercado, família e comunidade para concretizá-la, exige compreender como isso se constitui e quais suas interdependências.

Além disso, os limites impostos pelo capital para ampliação da proteção social pública, gratuita e universal, exige que se situe o lugar que o Estado-nação ocupa no sistema mundo capitalista e quais as possibilidades. Portanto, a análise parte de como a proteção social se concretiza em diferentes realidades sócio-históricas. 
Diante disso, identifica-se que mesmo havendo inúmeros estudos sobre a proteção social na América Latina permanece o desafio da realização de estudos comparados em uma perspectiva de totalidade concreta. Acredita-se que a partir desse método de compressão da realidade é possível realizar estudos que aprofundem o conhecimento sobre o tema na sua essência.

\section{O Giro Decolonial e suas Contribuições para a Proteção Social na América Latina}

A perspectiva decolonial parte da análise histórica do sistema mundo, fundada em um processo de hierarquização e interdependência entre os países. Defende que o debate democrático e horizontal é necessário para a construção de outra sociedade, com centralidade no valor da vida e não do mercado.

Nesse sentido, conforme Grosfoguel (2008, p. 132), na “América Latina, a maioria dos teóricos dependentistas privilegiam as relações econômicas em processos sociais, em detrimento das determinações de ordem cultural e ideológica." Isso causou dois problemas: subestimar as hierarquias coloniais/raciais e não conseguir explicar os complexos hierárquicos globais.

O autor afirma ser necessário superar tanto o reducionismo econômico quanto o culturalismo para uma intervenção decolonial. A dicotomia cultura versus economia advém da divisão de disciplinas, resultado do liberalismo enquanto geocultura do sistema-mundo moderno.

Grosfoguel (2008) se apoia na discussão de Wallerstein, apontando que essa separação em disciplinas autônomas é um empecilho para superar essa dicotomia e, ainda, concorda com a definição de capitalismo do autor enquanto "[...] uma rede integrada de processos econômicos, políticos e culturais, cuja soma garante a coesão do sistema" (WALLERSTEIN, 1991a apud GROSFOGUEL, 2008, p. 135).

Para o autor, o conceito de "Colonialidade do Poder", concebido por Aníbal Quijano, procura integrar no processo estrutural heterogêneo "as múltiplas relações em que os processos culturais, políticos e econômicos se enredam com o capitalismo enquanto sistema histórico." (GROSFOGUEL, 2008, p. 134). 
Quijano (2005, p. 117) demonstrou que com o processo de colonização da América se construiu hierarquias, lugares e papéis sociais correspondentes aos povos europeus e não europeus e, consequentemente, um padrão de dominação se impunha. Assim, "raça e identidade racial (índios, negros e mestiços) foram estabelecidas como instrumentos de classificação social básica da população" mundial.

A "raça" soma-se à divisão do trabalho e esses elementos foram estruturalmente associados e reforçados mutuamente. A utilização dos índios como mão de obra descartável e o trabalho escravo restrito, exclusivamente, à população africana, para Quijano (2005), desenvolveu a percepção entre os europeus ou brancos que o trabalho pago e protegido era privilégio dos brancos.

O autor aponta que o atual padrão de poder mundial é o primeiro global da história conhecida, onde estão articuladas as formas de controle das relações sociais: controle do trabalho; controle do sexo; controle da família burguesa; controle da autoridade, do Estado-nação; controle da intersubjetividade, o eurocentrismo. Há uma interdependência entre esses elementos, por isso o padrão de poder está configurado como um sistema, o sistema-mundo global. (QUIJANO, 2005).

Lugones (2008) irá incluir outros elementos na análise da colonialidade de poder e modernidade de Quijano², que considera central para o sistema de gênero. A construção da interseccionalidade de raça, gênero, classe, sexo procura dar visibilidade à dominação e violência das mulheres negras que não estão incluídas nas categorias isoladas de mulher ou negro.

A autora demostra que gênero não era um fator organizador da sociedade na América Latina antes do processo colonizador, portanto, tanto a visão binária do sexo quanto os atributos considerados masculinos e femininos advêm do eurocentrismo e com ele a dominação masculina.

\footnotetext{
2 Lugones (2008, p. 86) parte dos conceitos de Quijano de colonialidade do poder e modernidade para sua análise, porém, critica o autor por relacionar a discussão de sexo como fator biológico, negando a sua construção social. A autora afirma: "Esto nos lleva a ver el análisis del alcance del género en el capitalismo global eurocentrado de Quijano como bastante más limitado de lo que parece a primera vista. Allen razona que muchas comunidades tribales de Nativos Americanos eran matriarcales, reconocían positivamente tanto a la homosexualidad como al "tercer» género, y entendían al género en términos igualitarios, no en los términos de subordinación que el capitalismo eurocentrado les terminó por imponer."
} 
Portanto, o giro decolonial ${ }^{3}$ está em deslocar o lócus de enunciação da perspectiva do dominante para a perspectiva do dominado. Ao considerar o processo de colonização das Américas, Grosfoguel (2008) enumera nove hierarquias enredadas e coexistentes trazidas pelo homem heterossexual / branco/ patriarcal/ cristão/ militar/ capitalista/ europeu; são elas:

- Uma formação de classes de âmbito global em diferentes formas de trabalho, por exemplo, escravatura e trabalho assalariado irão coexistir e ser organizadas pelo capital;

- Divisão internacional do trabalho entre centro e periferia;

- Sistema interestatal de organizações político-militares;

- Hierarquia étnico-racial que privilegia os povos europeus;

- Hierarquia global que privilegia homens em relação às mulheres;

- Hierarquia sexual que privilegia heterossexuais;

- Hierarquia espiritual que privilegia cristãos;

- Hierarquia epistémica que privilegia conhecimentos ocidentais; e

- Hierarquia linguística entre as línguas europeias e não-europeias.

Essas múltiplas e heterogêneas hierarquias resultam das estruturas globais de poder e são integrantes, entretecidas e constitutivas do que Grosfoguel (2008) chama de sistema-mundo patriarcal/capitalista/colonial/ moderno europeu.

A complexidade do sistema-mundo exige uma análise na perspectiva da totalidade, em como se desenvolveram as relações de dominação entre os países e, mesmo após o rompimento jurídico-formal do colonialismo, essas relações permanecem, nas palavras de Quijano (2005), na forma de colonialidade no poder.

A contribuição da epistemologia decolonial para a análise da proteção social na América Latina se dá, principalmente, por duas vias. Primeiro, ao analisar a sociedade por

\footnotetext{
${ }^{3}$ A perspectiva decolonial iniciou com a resistência à dominação europeia no processo de colonização, por isso não se resume ao desenvolvimento da epistemologia decolonial na década de 1990. Essa perspectiva orienta ações e mudanças concretas, principalmente, do movimento negro e feminista. (COSTA; GROSFOGUEL, 2016).
} 
meio do entrelaçamento entre economia e cultura, considera a perspectiva da interseccionalidade raça/classe/gênero como estruturante do capitalismo periférico.

Os indígenas e negros (especialmente as mulheres negras) são os mais pobres na região, Samaha e Adelantado (2017) demonstram que a incidência de pobreza entre os povos indígenas ( $8,3 \%$ da população) e negros (aproximadamente $30 \%$ da população) varia de país para país, mas se situa entre 1,6 e 7,9 vezes acima do restante da população.

Contudo, o sistema de proteção social está voltado, prioritariamente, para os trabalhadores formais e urbanos, por meio do sistema contributivo, o que restringe o acesso à proteção social via contrato no mercado de trabalho em sociedades em que a informalidade atinge, aproximadamente, $50 \%$ da população economicamente ativa.

Na América Latina, os homens, de maior renda e com maior escolaridade, são os que mais contribuem para os sistemas de seguro social. A participação feminina no trabalho formal é de $56 \%$, enquanto a dos homens é de $83 \%$ na região, por isso no Chile e no Brasil, por exemplo, uma proporção significativa das mulheres acessam aposentadoria de forma indireta (pensão dos cônjuges). (OECD, 2015).

Os sistemas de proteção social não contributivos, por sua vez, têm como centralidade o combate à pobreza por meio de transferência condicionada de renda, com valores variáveis conforme a composição familiar, contudo, menores do que o salário mínimo nacional. O enfoque está no desenvolvimento de capacidades (por isso as condicionalidades de educação e saúde), o que individualiza o enfrentamento à pobreza e não a relaciona com o processo estrutural e histórico das sociedades latino-americanas.

Ademais, há preferência pela titularidade do benefício às mulheres ${ }^{4}$, sem uma discussão sobre a responsabilização delas pelo cumprimento de condicionalidades e o reforço a papéis sociais ligados à esfera doméstica e de cuidados, o que contribui para a manutenção de desigualdades econômicas e sociais de gênero.

Identifica-se que não há uma complementaridade entre as políticas contributivas e as políticas não contributivas, mas uma tensão entre o seguro e a assistência social, que faz com que parcela da população que está na informalidade, ou com renda insuficiente

\footnotetext{
${ }^{4}$ Segundo dados da CEPAL (2020), a pobreza atinge mais as crianças e adolescentes (menores de 15 anos), as mulheres e a população rural.
} 
para atender às suas necessidades sociais básicas, tenha dificuldades de acesso à política de proteção social pública.

Ademais, as políticas sociais de proteção social se desenvolvem desarticuladas das políticas econômicas de enfrentamento às desigualdades sociais, por isso, apesar de possibilitarem o acesso ao consumo de bens materiais indispensáveis para sobrevivência, não geram autonomia e possibilidades de participação social.

A segunda via de contribuição da perspectiva decolonial para a análise da proteção social na América Latina está relacionada com a primeira via, e se refere à discussão sobre o modelo de proteção social europeu que privilegia o homem-branco-assalariado, sendo sustentado pelo trabalho doméstico feminino não pago e não valorizado e que reforça hierarquias e papéis sociais de gênero representa uma das faces da colonialidade. Isso, somado às particularidades da formação sócio-histórica dos países da América Latina, recai no alto grau de responsabilidade de famílias e comunidades na proteção social, assim como a ação subsidiária do Estado.

Nesse sendo, identifica-se que a perspectiva decolonial contribui para análise da sociedade e, consequentemente, das formas de proteção social desenvolvidas na região, sendo necessário construir sistemas de proteção social a partir das necessidades sociais básicas da população e que rompam com o modelo europeu.

Tanto a análise da situação de pobreza que afeta mais negros e índios, quanto a análise da feminização da pobreza, se realizadas desconectadas do racismo estrutural e das desigualdades econômicas e sociais de gênero, recaem na culpabilização dos indivíduos por essa situação.

Para construção de sistemas de proteção social que respeitem as particularidades históricas e sociais dos países da América Latina, que promovam a valorização dos conhecimentos populares e a cultura local e, ainda, que se articulem com as políticas econômicas e se voltem às necessidades da população, faz-se necessário situar a discussão do lado subalterno das relações de poder.

A democratização e a participação social são elementos fundamentais em um processo de revisionismo das políticas de proteção social que é indispensável, uma vez que estão evidentes os limites da proteção social na região. 
O que pode ser demonstrado pela persistência da situação de pobreza que em 2019 afetava $28,7 \%$ da população, na região onde os $10 \%$ mais ricos concentram $37 \%$ da riqueza e os $40 \%$ mais pobres recebem apenas $13 \%$ da riqueza, segundo dados do Programa das Nações Unidas para o Desenvolvimento (PNUD, 2019).

Por fim, concorda-se com Aguiar (2016) quando a autora afirma que as teorias estudos subalternos e pós-colonialismo - são fecundas para a compreensão da realidade da América Latina porque promovem a renovação crítica do conhecimento em diferentes perspectivas: política, intelectual e de emancipação de situações de opressões de gênero, étnicas e raciais e de classe.

Nesse sentido, quanto melhor a análise da realidade, mais próxima da necessidade social serão as respostas dadas pelo Estado, por meio das políticas sociais, à classe trabalhadora, ou melhor, a ampliação deste debate pode contribuir para o fortalecimento de pautas dos movimentos sociais e movimentos reivindicatórios na região.

Assim, compreender os limites dos sistemas de proteção social existentes na região, que reproduzem e afirmam as hierarquias sociais impostas no processo de colonização, é um dos passos para provocar o debate sobre as mudanças indispensáveis nesses sistemas.

\section{Considerações Finais}

A análise da proteção social, na perspectiva decolonial, permitiu identificar elementos (in) visíveis na literatura sobre os sistemas de proteção social da América Latina e a necessidade de romper o elo com os estudos eurocentrados, uma vez que eles limitam o conhecimento da realidade concreta da região, falseando a realidade.

Além disso, os estudos da realidade social que desconsideram as hierarquias impostas socialmente e reproduzidas desde o processo de colonialismo podem estar sustentando ações e iniciativas de proteção social que mantêm e reforçam essas hierarquias.

Isso pode ser percebido quando, na primeira seção, foram demonstrados os limites dos sistemas de proteção social europeus, que privilegiavam o homem, branco, 
inserido no mercado de trabalho formal e sustentado no trabalho doméstico feminino não pago e não valorizado.

Contudo, esses elementos não aparecem nos estudos comparados, os quais privilegiam dados quantitativos e as categorias familismo/desfamilismo e mercadorização/ desmercadorização. Em relação às teorias explicativas, percebe-se que há poucos estudos e aqueles que existem voltam-se para aspectos econômicos, políticos e grau de participação social.

Na segunda seção, a discussão centralizou-se na discussão sobre a perspectiva decolonial e suas contribuições para a análise da proteção social. Demonstra a centralidade no sistema contributivo que perpetua desigualdades e as fragilidades do sistema não contributivo em relação à individualização do combate à pobreza e aos valores abaixo do necessário para o atendimento das necessidades sociais.

As contribuições partem da perspectiva epistemológica que entrelaça economia e cultura; considera a perspectiva da interseccionalidade raça/classe/gênero como estruturante do capitalismo periférico; e demonstra que o sistema de proteção social europeu, transportado para América, reforça hierarquias e papéis sociais de classe, raça, gênero, sendo, portanto, uma das faces da colonialidade.

\section{Referências}

AGUIAR, J. D. N. Teoria pós-colonial, estudos subalternos e américa latina: uma guinada epistemológica? Revista Estudos de Sociologia, Araraquara, v. 21, n. 41, p. 273-289, jul./dez. 2016.

ALENCAR, T. R. Processos de generificação e racialização nas políticas públicas de bemestar social: o caso do Reino Unido. Revista Marx e o Marxismo, Niterói, v. 7, n. 12, p. 3864, jan./jun. 2019.

ANDRADE, F. F. Regimes de proteção social na América Latina: modelos e tendências recentes. Revista Emancipação, Ponta Grossa, v. 12, p. 21-33, mar. 2012.

ANTÍA, F. Regímenes de política social en América Latina: una revisión crítica de la literatura. Desafíos, Bogotá, p. 193-235, 2. sem. 2018.

ARRETCHE, M. Emergência e desenvolvimento do welfare state: teorias explicativas. BIB, Rio de Janeiro, n. 39, 1. sem., p. 3-40, 1995. Disponível em: 
https://www.anpocs.com/index.php/bib-pt/bib-39/452-emergencia-e-desenvolvimentodo-welfare-state-teorias-explicativas/file. Acesso em: 5 set. 2020.

CEPAL, Comissão Econômica para a América Latina e o Caribe. Panorama Social da América Latina, ano 2019. Resumo executivo. Chile: Santiago, 2020. Disponível em: https://repositorio.cepal.org/bitstream/handle/11362/45090/1/S1900909_pt.pdf. Acesso em: 5 set. 2020.

CEPAL (1998), Comissão Econômica para a América Latina e o Caribe. Panorama Social da América Latina, ano 1997. Resumo executivo. Chile: Santiago, 1998. Disponível em: https://repositorio.cepal.org/bitstream/handle/11362/1254/S979789_es.pdf?sequence= 1\&isAllowed=y. Acesso em: 5 set. 2020

COSTA, J. B.; GROSFOGUEL, R. Decolonialidade e perspectiva negra. Revista Sociedade e Estado, Brasília, v. 31, n. 1, p. 15-24, jan./abr. 2016.

CUNHA, E. P. Karl Marx: elementos da determinação material da burocracia de Estado. In: CUNHA, E. P. Marxismo e burocracia de estado. Campinas: Papel Social, 2017. p. 15-38.

ESPING-ANDERSEN, G. As três economias políticas do Welfare State. Revista Lua Nova, São Paulo, n. 24, p. 85-116, 1991.

GIOVANNI, G. Sistemas de proteção social: uma introdução conceitual. In: OLIVEIRA, M. A. (org.). Reforma do Estado: políticas de emprego no Brasil. Campinas: Unicamp, 1998. p. 929.

GROSFOGUEL, R. Para descolonizar os estudos de economia política e os estudos póscoloniais: transmodernidade, pensamento de fronteira e colonialidade global. Revista Crítica de Ciências Sociais, Coimbra, n. 80, p. 115-147, mar. 2008.

KERSTENETZKY, C. L. O Estado do bem-estar social na idade da razão: a reinvenção do estado social no mundo contemporâneo. Rio de Janeiro: Elsevier, 2012.

KRAWCZYK, N. R.; MORAES, R. C. C. Estudos comparados, projeto histórico e análise de políticas públicas: entrevista com Hugo Zemelman. Revista Educação \& Sociedade, Campinas, v. 24, n. 82; p. 311-320, abr. 2003.

LUGONES, M. Colonialidad y género. Tabula Rasa, Bogotá, n. 9, p. 73-101, jul./dez. 2008.

MARX, K. O capital. São Paulo: Boitempo, 2013. Livro I.

OECD. Organização para Cooperação e Desenvolvimento Econômico. Um panorama dos sistemas previdenciários na América Latina e no Caribe. Brasília, DF: OECD, 2015

PEREIRA, C. P. Proteção social no capitalismo: contribuições à crítica de matrizes teóricas e ideológicas conflitantes. 2013. Tese (Doutorado em Política Social) - Universidade de Brasília, Brasília, 2013. 
PNUD. Programa das Nações Unidas para o Desenvolvimento. Relatório do desenvolvimento humano. New York: PNUD, 2019.

QUIJANO, A. Colonialidade do poder, eurocentrismo e América Latina. In: CLACSO. A colonialidade do saber: eurocentrismo e ciências sociais. Buenos Aires: Perspectivas Latino-Americanas, 2005. p. 117-142.

SAMAHA, M. J.; ADELANTADO, J. Diversidade étnica e regimes de bem-estar na América latina. In: COSTA, L. C.; DEL VALLE, A. H. A seguridade social no Brasil e na Argentina: os direitos sociais em tempos de ajustes neoliberais. Guarapuava: Unicentro, 2017. p. 31-52.

VIANA, A. L. d'.; FONSECA, A. M. M.; SILVA, H. P. Proteção social na América Latina e Caribe: mudanças, contradições e limites. Caderno Saúde Pública, Rio de Janeiro, v. 33, 2017.

VIANNA, M. L. T. W. A americanização (perversa) da seguridade social no Brasil: estratégias de bem-estar e políticas públicas. 3. ed. Rio de Janeiro: Revan: UCAM, IUPERJ, 2011. 